\title{
Clinical Characteristics, Molecular Features, and Long-Term Follow-Up of 15 Patients with Neonatal Diabetes: A Single-Centre Experience
}

\author{
Zehra Yavas Abali $^{a} \quad$ Elisa De Franco ${ }^{b}$ Esin Karakilic Ozturan ${ }^{a}$ \\ Sukran Poyrazoglu ${ }^{a}$ Ruveyde Bundak ${ }^{a} \quad$ Firdevs Bas $^{a}$ Sarah E. Flanagan ${ }^{b}$ \\ Feyza Darendeliler ${ }^{a}$ \\ aDepartment of Paediatric Endocrinology and Diabetes, Istanbul Faculty of Medicine, Istanbul University, Istanbul, \\ Turkey; ${ }^{b}$ Institute of Biomedical and Clinical Science, University of Exeter Medical School, Exeter, UK
}

\section{Keywords}

Neonatal diabetes - Monogenic diabetes of infancy $\cdot A B C C 8$.

KCNJ11 P PTF1A · EIF2AK3 - INS · SLC19A2

\begin{abstract}
Background: Diabetes diagnosed within the first 6 months of life is defined as neonatal diabetes mellitus (NDM). Mutations in the KCNJ11, $A B C C 8$, and INS genes are the most common cause of permanent NDM. In populations with a high rate of consanguinity, Wolcott-Rallison syndrome caused by biallelic EIF2AK3 mutations is common. Methods: We studied the clinical characteristics and underlying genetic cause of disease in 15 individuals with diabetes onset before 6 months of age as defined by sustained hyperglycaemia requiring insulin treatment. Patients who had a remission of the diabetes, defined by a normal blood glucose and HbA1C value without insulin or sulphonylurea (SU) treatment, within the first 18 months of life were classified as having transient NDM (TNDM). Results: We report 15 patients with NDM from 14 unrelated families, including 10 with reported parental consanguinity. 1/15 patients had a remission of diabetes, leading to a diagnosis of TNDM. Mutations were detected in $80 \%(n=12 / 15)$ of the cohort (ABCC8 $[n=4]$, PTF1A-
\end{abstract}

distal enhancer [ $n=3], K C N J 11[n=2], \operatorname{EIF} 2 A K 3[n=1]$, INS $[n=1]$, and SLC19A2 [ $n=1])$. All cases were initially treated with multiple dose insulin injections. One patient with an $A B C C 8$ mutation transitioned from insulin to SU resulting in improved metabolic control at the age of 20 years. Conclusion: Although the number of individuals born to consanguineous parents was considerably high in this cohort, KATP channel mutations ( $A B C C 8 / K C N J 11)$ were more common than EIF2AK3 mutations ( $n=6$ vs. $n=1$ ). Genetic analyses should be performed in all NDM cases due to the potential impact on treatment and prognosis. @ 2021 S. Karger AG, Basel

\section{Introduction}

Diabetes diagnosed within the first 6 months of life is defined as neonatal diabetes mellitus (NDM). In approximately $82 \%$ of cases, a monogenic aetiology is identified $[1,2]$. NDM can be sub-grouped according to whether the diabetes is transient (TNDM) or permanent (PNDM). TNDM occurs in approximately half of the cases; in these patients, the diabetes usually resolves within a few months after onset but may relapse later in life [3]. Rare syn- karger@karger.com

www.karger.com/hrp

(c) 2021 S. Karger AG, Base

Karger ${ }^{\prime}=$
Zehra Yavas Abali

Department of Paediatric Endocrinology and Diabetes Istanbul University Istanbul Faculty of Medicine

Turgut Ozal Millet Cd Fatih, TR-34093 Istanbul (Turkey)

zehra_yavas@yahoo.com 
dromes which feature NDM also exist; these constitute a third sub-group, syndromic NDM.

The incidence of NDM varies regionally. In European populations, it affects approximately 1 in 90,000-160,000 live births [2-4]. A higher incidence of disease is reported in populations with high consanguinity rates. For example, in the Southeast Anatolia Region of Turkey, the incidence is approximately 1 in 48,000 live births [5], whilst in the Middle East, PNDM affects 1 in 21,000 live births [6].

Mutations in the KCNJ11 and $A B C C 8$ genes are the most common cause of PNDM accounting for approximately $50 \%$ of cases in outbred populations [1,7-9]. KCNJ11 and ABCC8 encode the ATP-sensitive (KATP) channel, and for approximately $90 \%$ of patients with a mutation in these genes, there is a marked improvement in glycaemic control following transfer from insulin injections to sulfonylurea (SU) therapy [7, 9-11]. This provides one of the best examples of precision medicine whereby understanding the underlying molecular mechanism of disease results in disease-specific therapy and improved outcome.

Biallelic mutations in the EIF2AK3 gene, encoding the eukaryotic translation initiation factor 2 - $\alpha$ kinase 3 (also known as PERK), cause the rare and often fatal WolcottRallison syndrome (WRS). This is the most common cause of PNDM in countries with high consanguinity rate [12]. PERK expression in multiple tissues explains the range of clinical manifestations, typically including infancy-onset diabetes, skeletal dysplasia, and liver dysfunction $[13,14]$.

Monogenic diabetes is clinically and genetically heterogeneous, with mutations in at least 36 genes reported [15]. Early comprehensive testing of all the causative genes using targeted next-generation sequencing provides an early genetic diagnosis which will guide the clinical management strategies [2].

In this study, we describe the clinical features, longterm follow-up, and underlying molecular aetiologies in a cohort of 15 NDM patients. We analyze the phenotypic characteristics, treatment decisions, and the impact of understanding the molecular aetiology on prognosis.

\section{Subjects and Methods}

We studied 15 patients with NDM (1 female) from 14 unrelated families followed in the Pediatric Endocrinology and Diabetes Unit, Istanbul Faculty of Medicine. Inclusion criteria were diabetes onset below 6 months of age (defined by hyperglycaemia and insulin requirement for at least 2 weeks). Individuals with stress- related or drug-induced hyperglycaemia were excluded. Patients who initially presented with hyperglycaemia followed by normal blood glucose and normal $\mathrm{HbAlc}$ values without insulin or $\mathrm{SU}$ requirement under 18 months of age were defined as having TNDM.

Data on the diagnosis and treatment of diabetes, family history, and other clinical features were obtained from the medical records. Autoantibodies including anti-glutamic acid decarboxylase (AntiGAD), islet cell antibody (ICA), and anti-insulin antibody (AIA) were recorded. The transfer to $\mathrm{SU}$ was carried out using a standard protocol similar to that described previously [7] (available at https://www.diabetesgenes.org/about-neonatal-diabetes/).

\section{Molecular Analyses}

Genomic DNA was extracted from peripheral leukocytes of patients using standard procedures. Genetic testing was performed at the Exeter Genomics Laboratory as previously described [1]. For 12 patients, the KATP channel genes (ABCC8 and KCNJ11), INS, and EIF2AK3 were initially tested using Sanger sequencing to analyze the coding regions and conserved splice sites. In patients without a pathogenic variant, analysis of all the other known genetic causes of neonatal diabetes (EIF2AK3, FOXP3, GATA4, GATA6, GCK, GLIS3, HNF1B, IER3IP1, IL2RA, LRBA, PDX1, PTF1A including the distal enhancer, NEUROD1, NEUROG3, NKX2-2, RFX6, SLC2A2, SLC19A2, STAT3, and WFS1) was performed using a targeted next-generation sequencing assay as previously described [16]. This assay can also detect partial or whole gene deletions and duplications. All mutations detected by this method were confirmed using Sanger sequencing analysis of the mutated exon in the affected gene. Family members were tested only for the mutation detected in the probands. In 1 patient, Sanger sequencing of only the $A B C C 8, K C N J 11, I N S$, and GCK genes was undertaken as the family did not consent to additional genetic testing. In $2 \mathrm{pa}-$ tients without a genetic diagnosis, genetic testing was not performed.

\section{Statistical Analysis}

Statistical analysis was performed using SPSS 21.0 for Windows statistical software. Data were expressed as mean \pm SD. A $p$ value of $\leq 0.05$ was considered to be statistically significant.

\section{Results}

\section{Clinical Characteristics of Patients with NDM}

Clinical, biochemical, and molecular characteristics of patients at admission and at last evaluation are provided in Tables 1 and 2. Fifteen patients (2 siblings) were diagnosed with NDM requiring multiple dose insulin (MDI) injection. The mean age at diagnosis was $2.4 \pm 1.5$ months (median 2.0, range 0.2-6.0 months). Gestational ages ranged between 35 and 40 gestational weeks (GW). Birth weight (BW) was between 1,400 and 3,680 g, and the BWSDS was $-1.7 \pm 1.7$ (median -1.1 ). The small for gestational age (SGA, BW <-2.0 SDS) ratio was $40 \%$. The mean serum glucose level at diagnosis was $529.2 \pm 160.0$ 
Table 1. Clinical, biochemical, and molecular characteristics of the patients at diagnosis

\begin{tabular}{|c|c|c|c|c|c|c|c|c|c|c|c|c|c|}
\hline Patient & $\begin{array}{l}\text { Sex } \\
(M / F)\end{array}$ & GW & $\begin{array}{l}\text { BW, kg } \\
\text { (SDS) }\end{array}$ & $\begin{array}{l}\text { Parental } \\
\text { con- } \\
\text { sanguinity }\end{array}$ & $\begin{array}{l}\text { Family } \\
\text { member } \\
\text { with } \mathrm{DM}^{\mathrm{c}}\end{array}$ & $\begin{array}{l}\text { Age at } \\
\text { diagnosis, } \\
\text { months }\end{array}$ & $\begin{array}{l}\text { Plasma } \\
\text { glucose, } \\
\mathrm{mg} / \mathrm{dL}\end{array}$ & $\begin{array}{l}\text { Urinary } \\
\text { ketone }\end{array}$ & $\begin{array}{l}\text { Serum } \\
\text { insulin, } \\
\mu U / m L\end{array}$ & $\begin{array}{l}\text { C-peptide, } \\
\mathrm{ng} / \mathrm{mL}\end{array}$ & \multicolumn{2}{|c|}{$\begin{array}{l}\text { Seizure at DKA at } \\
\text { diagnosis diagnosis }\end{array}$} & Molecular diagnosis \\
\hline $2^{\mathrm{a}}$ & M & 39 & $2.7(-1.8)$ & Yes & $(+)$ & 2.5 & 520 & $(-)$ & na & na & $(-)$ & $(-)$ & $\begin{array}{l}A B C C 8 \\
\text { Homozygous p.E382K }\end{array}$ \\
\hline 4 & M & 39 & $3.1(-0.6)$ & Yes & na & 2.0 & 520 & $(-)$ & 0.6 & 0.14 & $(-)$ & $(-)$ & $\begin{array}{l}\text { ABCC8 } \\
\text { Compound } \\
\text { heterozygous } \\
\text { p.I557R/p.R1145L }\end{array}$ \\
\hline 6 & M & 35 & $1.5(-3.1)$ & No & $(-)$ & 0.2 & 500 & na & na & 0.01 & $(-)$ & $(-)$ & $\begin{array}{l}P T F 1 A \text {-distal enhancer } \\
\text { Homozygous } \\
\text { g.23508437A }>\mathrm{G}\end{array}$ \\
\hline 7 & $\mathrm{~F}$ & 39 & $1.4(-5.5)$ & No & $(+)$ & 0.5 & 522 & $(-)$ & na & 0.011 & $(-)$ & $(-)$ & $\begin{array}{l}P T F 1 A \text {-distal enhancer } \\
\text { Homozygous } \\
\text { g.23508437A }>\mathrm{G}\end{array}$ \\
\hline 8 & M & 38 & $2.9(-0.8)$ & No & $(-)$ & 3.0 & 900 & $(+)$ & na & 0.33 & $(-)$ & $(+)$ & $\begin{array}{l}\text { KCNJ11 } \\
\text { Heterozygous } \\
\text { p.E322K }\end{array}$ \\
\hline 9 & M & 38 & $2.5(-2.5)$ & No & $(-)$ & 1.0 & 695 & $(+)$ & na & na & $(-)$ & $(-)$ & $\begin{array}{l}\text { KCNJ11 } \\
\text { Heterozygous } \\
\text { p.R201C }\end{array}$ \\
\hline 12 & M & 39 & $3.01(-0.9)$ & Yes & $(-)$ & 3.0 & 400 & $(-)$ & 3.0 & 1.14 & $(-)$ & $(-)$ & $\begin{array}{l}\text { SLC19A2 } \\
\text { Homozygous } \\
\text { p.S214fs*14 }\end{array}$ \\
\hline 13 & M & 38 & $3.1(-0.2)$ & Yes & $(-)$ & 3.0 & 564 & $(+)$ & 0.2 & 0.22 & $(-)$ & $(+)$ & $n a^{b}$ \\
\hline 14 & M & 39 & $3.3(-0.1)$ & 1 & $(-)$ & 1.0 & 792 & na & na & na & $(-)$ & $(+)$ & $n a^{b}$ \\
\hline 15 & M & 40 & $3.68(0.6)$ & No & $(-)$ & 5.9 & 477 & na & na & 0.3 & $(-)$ & $(-)$ & $\mathrm{na}^{\mathrm{b}}$ \\
\hline
\end{tabular}

Conversion factor for glucose: $\mathrm{mmol} / \mathrm{L}$ in $\mathrm{mg} / \mathrm{dL}$; conversion factor: $1 \mathrm{mmol} / \mathrm{L}=18,018 \mathrm{mg} / \mathrm{dL}$. M, male; F, female; GW, gestational week; BW, birth

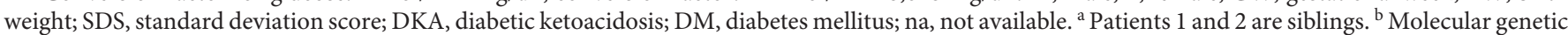
studies could not be performed in 3 patients ( $\mathrm{P} \# 13,14$, and 15) because the family did not approve genetic testing. In $\mathrm{P} \# 15$, sequencing analysis of the $A B C C 8$, KCNJ11, INS, and GCK genes was negative; parental consent was not obtained for further genetic testing in this case. ${ }^{\mathrm{c}}$ Family members with DM were diagnosed as type 2 diabetes, and they were on oral anti-diabetic therapy. Mother of $\mathrm{P} \# 11$ had diabetes diagnosed at 41 years of age requiring oral anti-diabetic initially and afterwards insulin. Segregation analyses of these family members (except parents) could not be performed at that time period. 
Table 2. Clinical, biochemical, and molecular characteristics of 10 patients at last evaluation

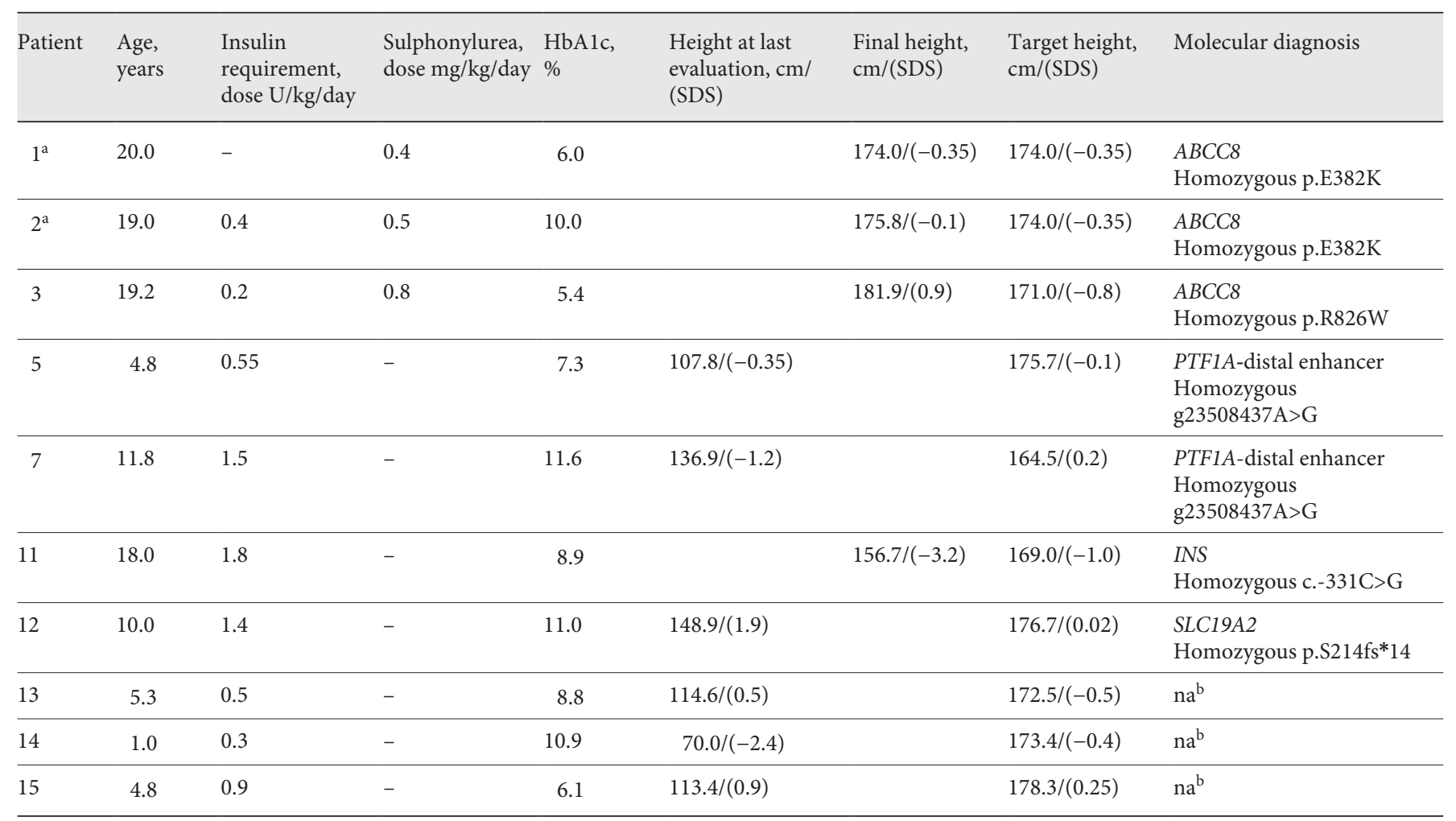

${ }^{a}$ Patients 1 and 2 are siblings. ${ }^{b}$ Molecular genetic studies could not be performed in 3 patients (P\#13, 14, and 15) because the family did not approve genetic testing. In P\#15, sequencing analysis of the ABCC8, KCNJ11, INS, and GCK genes was negative; parental consent was not obtained for further genetic testing in this case.

$\mathrm{mg} / \mathrm{dL}(29.4 \pm 8.9 \mathrm{mmol} / \mathrm{L})$. Three patients $(20 \%) \mathrm{had}$ diabetic ketoacidosis (DKA) at diagnosis. Seizures were the presenting complaint in $2(13.3 \%)$ patients.

Ten patients were born to consanguineous parents (9/14 families, $64.2 \%)$. Mutations were identified in 6 different genes in $80 \%$ of the cohort $(12 / 15)(A B C C 8[n=4$, 2 siblings], PTF1A-distal enhancer [ $n=3], K C N J 11[n=$ 2], EIF2AK3 [ $n=1]$, INS [ $n=1]$, and SLC19A2 [ $n=1])$. In 3 patients, comprehensive genetic testing of all known NDM genes was not possible. The distribution of NDM cases according to molecular aetiology is illustrated in Figure 1.

\section{NDM due to ABCC8 Mutations}

Two siblings ( $\mathrm{P} \# 1$ and $\mathrm{P} \# 2$ ) in our cohort were diagnosed with diabetes at the age of 5 and 2.5 months, respectively. After the genetic diagnosis of $A B C C 8$-NDM was established in these cases, transfer from insulin therapy to SU was attempted at 15.2 years of age in $\mathrm{P} \# 1$ and 10.7 years of age in $\mathrm{P} \# 2$. Insulin requirements decreased by
$50 \%$ within a week, and C-peptide levels increased from 0.07 to 2.2 ( $N: 1.4-4.4 \mathrm{ng} / \mathrm{mL}$ ) and from 0.17 to $2.0 \mathrm{ng} / \mathrm{mL}$ in $\mathrm{P} \# 1$ and $\mathrm{P \# 2}$, respectively. Insulin therapy was ceased at the end of 2 months in both patients. These 2 patients were previously described by Aydin et al. [17]. Currently, $\mathrm{P} \# 1$ has been only on SU therapy for 4 years and his last $\mathrm{HbA1c}$ level was 6.7\%. However, because of hyperglycaemia and increased HbA1c levels in P\#2, MDI treatment (insulin aspart and glargine) was added at the age of 16 years. It was stated that compliance to SU treatment was appropriate. At last evaluation at 19 years old, he was using both glibenclamide and insulin treatment. Both of the siblings had no diabetic complications. Neurodevelopment is normal.

$\mathrm{P} \# 3$ presented with seizures and hyperglycaemia without acidosis at the age of 1.5 months. He was treated with MDI (insulin lispro and glargine), and the dose was increased up to $1.0 \mathrm{U} / \mathrm{kg} /$ day. A homozygous $A B C C 8$ mutation (p.R826W) was detected, and treatment was switched to $\mathrm{SU}$ at the age of 16.3 years. $\mathrm{HbA1c}$ was $7.5 \%$ before $\mathrm{SU}$. 
Fig. 1. Distribution of neonatal diabetes mellitus cases according to molecular aetiology. ABCC8, $n=4$ (26.6\%); PTF1A enhancer, $n=3(20 \%)$; KCNJ11, $n=2(13.3 \%)$; EIF2AK3, $n=1$ (6.7\%); INS, $n=1(6.7 \%)$; SLC19A2, $n=1$ (6.7\%); unknown, $n=3$ (20\%).

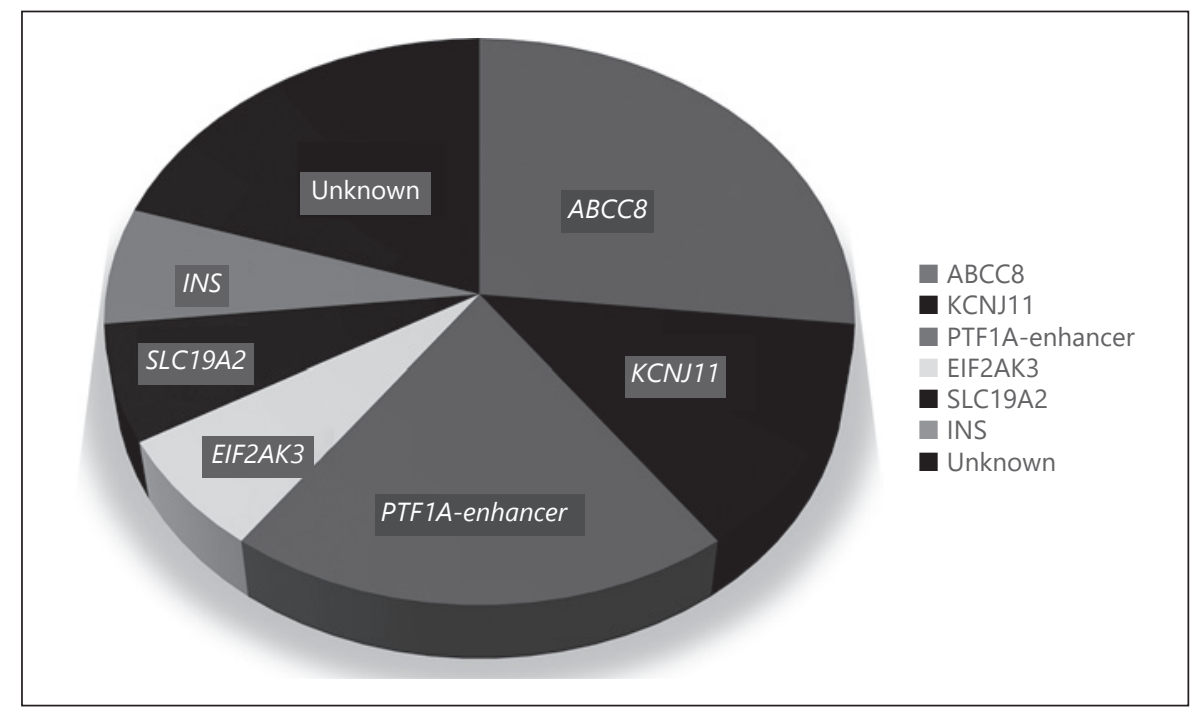

After glibenclamide treatment, insulin requirement decreased by $50 \%$ on both SU and MDI. Between 17.2 and 19.2 years of age, $\mathrm{SU}$ and insulin requirements were 0.8 $\mathrm{mg} / \mathrm{kg} /$ day and $0.2 \mathrm{U} / \mathrm{kg} /$ day (insulin glargine only), respectively. Diabetic complications were not observed.

$\mathrm{P} \# 4$ was diagnosed with NDM at 2 months of age, and compound heterozygous ABCC8 mutation p.(I557R/ R1145L) was detected. Follow-up data for this patient were not available, and it is not known if SU transfer has been attempted.

\section{NDM due to PTF1A Mutations}

Three patients in our cohort had NDM due to a recessive mutation in the PTF1A-distal enhancer (P\#5,6, and 7). All 3 patients had severe SGA. P\#5 was diagnosed with $\mathrm{NDM}$ at 2.2 months of age. He had a triangular face with small chin, and his head circumference was 10-25th centile. His basal serum insulin and C-peptide levels were 0.4 $\mu \mathrm{U} / \mathrm{mL}$ and $0.12 \mathrm{ng} / \mathrm{mL}$, respectively. Following the diagnosis of NDM, NPH insulin $(0.5 \mathrm{U} / \mathrm{kg} /$ day $)$ was commenced. Ultrasonography revealed hypoplastic pancreas (5-mm pancreas corpus), and faecal elastase was low confirming exocrine pancreatic insufficiency. An atrial septal defect of secundum type was also observed. The patient had a history of seizures during follow-up, and phenobarbital was added. The previously reported [18] homozygous g.23508437A $>\mathrm{G}$ mutation was detected in the PTF1A-distal enhancer. His unaffected parents were heterozygous for the mutation.

P\#6 was diagnosed with diabetes at 6 days old, in Iraq. The patient was admitted to our emergency unit at 36 days old at which point plasma glucose was $600 \mathrm{mg} / \mathrm{dL}$ (33.3 mmol/L) with extremely low C-peptide concentration $(0.01 \mathrm{ng} / \mathrm{mL}, \mathrm{N}: 1.4-4.4)$. He had fatty stools suggesting exocrine pancreatic insufficiency. Abdominal ultrasonography revealed pancreatic hypoplasia. Echocardiography was normal. Initial insulin requirement was $0.2 \mathrm{U} / \mathrm{kg} /$ day. Genetic testing identified the same homozygous g.23508437A $>\mathrm{G}$ mutation in the PTF1A-distal enhancer detected in $\mathrm{P} \# 5$.

$\mathrm{P} \# 7$ was referred at 15 days old due to swelling of the face and legs. She had severe hyperglycaemia without metabolic acidosis requiring full replacement insulin treatment $(1.0 \mathrm{U} / \mathrm{kg} /$ day $)$. Her unaffected parents were from the Eastern region of Turkey and were non-consanguineous. Hypoalbuminemia $(1.7 \mathrm{~g} / \mathrm{dL})$ and anaemia were observed, and she was transfused. Coarse face with micrognathism was also observed. The head circumference was -2.8 SDS. Echocardiography was normal. Chymotryptic activity was low, and pancreatic hypoplasia was detected on ultrasonography. Pancreatic enzyme replacement treatment was commenced. Genetic testing identified the homozygous g.23508437A $>\mathrm{G}$ mutation in the PTF1A-distal enhancer; her parents were heterozygous carriers. The family was non-compliant, and HbA1c levels of the subject were often $>10.0 \%$ despite intensive education.

\section{NDM due to KCNJ11 Mutations}

Two patients in our cohort had NDM caused by activating KCNJ11 mutations (P\#8 and 9). $\mathrm{P} \# 8$ was admitted with fever at 3 months of age. He was treated for DKA, 
and after recovery, MDI treatment at a dose of $0.3 \mathrm{U} / \mathrm{kg} /$ day was continued. During the first year of treatment, insulin requirement was decreased and he used only insulin in stress conditions such as infections. A heterozygous KCNJ11 mutation (p.E322K) was detected. He had been followed in our institution until the age of 3 years. His developmental milestones were normal for age, and transfer to SU was not attempted during this period (no further follow-up available).

$\mathrm{P} \#$ 9 was referred for fever and irritability at 1 month of age. Hyperglycaemia was detected without DKA. MDI regimen (regular short acting and NPH) was commenced. A heterozygous p.R201C KCNJ11 mutation was detected. Transfer to SU was not attempted whilst this patient was under the care of our centre. Follow-up data after the age of 2 years are not available.

NDM due to EIF2AK3, INS, and SLC19A2 Mutations $\mathrm{P} \# 10$ was diagnosed with NDM at 6 months of age. Parents of $\mathrm{P} \# 10$ were second-degree cousins without any family history of diabetes. P\#10 did not have any skeletal findings or liver abnormalities at admission. Molecular genetic testing identified a homozygous EIF2AK3 (p.L742*) mutation, confirming a diagnosis of WolcottRallison syndrome. He died of acute liver failure in a different centre (age not known).

P\#11 was referred for severe hyperglycaemia and diagnosed with NDM at the age of 20 days. Parents were related, and his mother had diabetes diagnosed at 41 years requiring oral anti-diabetic initially and afterwards insulin. Systemic examination was unremarkable. MDI treatment (regular short acting and $\mathrm{NPH})$ was initiated $(0.5 \mathrm{U} /$ $\mathrm{kg}$ /day). At his last evaluation at 9.5 years of age, his weight and height were $21.5 \mathrm{~kg}(-2.3 \mathrm{SDS})$ and $119.0 \mathrm{~cm}$ $(-2.8 \mathrm{SDS})$, respectively. The total insulin dose was $0.8 \mathrm{U} /$ $\mathrm{kg} /$ day with an $\mathrm{HbA} 1 \mathrm{c}$ level of $10.0 \%$. A homozygous INS promoter mutation, c.-331C $>\mathrm{G}$, was detected. He had no regular follow-up visits after 9.5 years of age. He was recalled and evaluated at 18 years of age. Neurodevelopment was normal. The total insulin requirement on MDI regimen (short-acting insulin and $\mathrm{NPH}$ ) was $1.8 \mathrm{U} / \mathrm{kg}$ / day.

$\mathrm{P} \# 12$ was evaluated for being pale and weak at 3 months of age at which point biochemical studies identified a low haemoglobin (Hb: $6.9 \mathrm{~g} / \mathrm{dL}$ ) and high plasma glucose (400 mg/dL, $22.2 \mathrm{mmol} / \mathrm{L})$. Insulin and C-peptide levels were low. MDI treatment (insulin lispro and insulin detemir) was commenced $(0.5-0.7 \mathrm{U} / \mathrm{kg} /$ day). Anaemia with poikilocytosis was detected. The mean corpuscular volume (MCV) was $89.0 \mathrm{fL}$, and the vitamin B12 concen- tration was $378 \mathrm{ng} / \mathrm{L}(\mathrm{N}: 191-663)$ at admission. Because of severe anaemia, blood transfusion was performed. Echocardiography was normal. Sensorineural deafness was detected at 14 months of age. He had been also followed for $1^{\circ}$ atrioventricular block. Genetic testing identified a homozygous frameshift mutation in the SLC19A2 gene (p.S214fs*14) confirming a diagnosis of thiamine responsive megaloblastic anaemia (TRMA, Rogers syndrome). His unaffected parents were heterozygous carriers. Thiamine was added to the treatment, and the anaemia resolved.

\section{In 3 Cases, Comprehensive Molecular Genetic Testing} Could Not Be Performed

$\mathrm{P} \# 13$ presented at 3 months of age with fever and vomiting after vaccination. Severe hyperglycaemia, ketonuria, and metabolic acidosis (bicarbonate: $4.7 \mathrm{mmol} / \mathrm{L}$ ) were detected. Insulin and C-peptide levels at diagnosis were low, and diabetes autoantibodies were negative. Cranial, abdominal ultrasonography and fundoscopic examination were normal. Low free T4 (FT4) and inappropriately normal TSH concentrations in 2 different measurements (FT4: 11.3 pmol/L [12-22], TSH: $5.9 \mathrm{mIU} / \mathrm{L}$ [0.27-4.9]; FT4: 11.0 pmol/L [12-22], TSH: $3.42 \mathrm{mIU} / \mathrm{L}$ [0.27-4.9]) were detected, at the age of 4 months. Differential diagnosis was non-thyroidal illness (euthyroid sick syndrome) or central hypothyroidism. Since these measurements were performed 1 month after the initial diagnosis of diabetes with no any other confounding disease, the possibility of non-thyroidal illness was low. However, central hypothyroidism could not be excluded. Serum basal cortisol concentration was normal $(16.0 \mu \mathrm{g} / \mathrm{dL})$, and TSH was increased (peak TSH level $53 \mathrm{mIU} / \mathrm{L}$ ) after the TRH stimulation test. In this young infant, L-thyroxine replacement was commenced to prevent any complication of hypothyroidism. During follow-up, L-thyroxine dose requirement per weight decreased gradually and treatment was stopped at 3 years of age suggesting a transient hypothyroidism. The haemoglobin level was $8.4 \mathrm{~g} / \mathrm{dL}$ (lower limit for age: $9.4 \mathrm{~g} / \mathrm{dL}$ ) with MCV $78.9 \mathrm{fL}$ (lower limit for age $84 \mathrm{fL}$ ), and oral iron replacement was also added. Parental consent for genetic testing could not be obtained.

P\#14 presented with fever and vomiting at the age of 30 days. Metabolic acidosis and hyperglycaemia $(792 \mathrm{mg} /$ dL) were detected. After recovery of DKA, MDI (NPH and insulin aspart) was started $(0.5-0.6 \mathrm{U} / \mathrm{kg} /$ day). Thyroid function and tests for pancreatic exocrine function were normal. Neurodevelopmental milestones were normal. His last evaluation was at 13 months of age, and the $\mathrm{HbAlc}$ was $10.9 \%$ with an insulin dose of $0.3 \mathrm{U} / \mathrm{kg} /$ day 


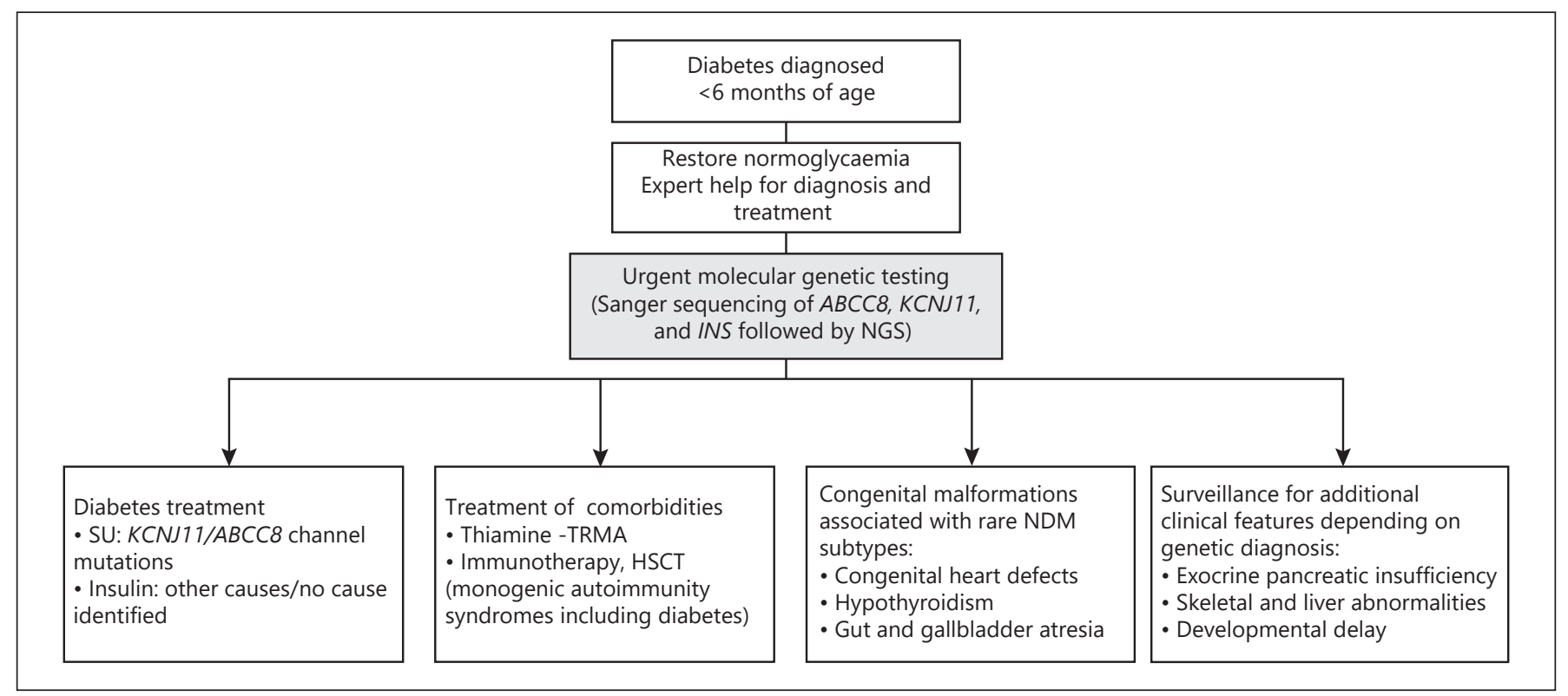

Fig. 2. A pipeline for the diagnosis and follow-up of NDM cases. NDM, neonatal diabetes mellitus; NGS, nextgeneration sequencing; SU, sulphonylurea; TNDM, transient neonatal diabetes mellitus; TRMA, thiamine responsive megaloblastic anaemia; HSCT, haematopoietic stem cell transplantation.

(insulin detemir only, rarely insulin aspart). Molecular analysis was not performed.

P\#15 was diagnosed at 5.9 months of age with extremely high plasma glucose. There was no family history of diabetes. Autoantibodies were negative, and C-peptide was low. He had no dysmorphic features or evidence of exocrine pancreatic insufficiency. MDI regimen (regular short acting and $\mathrm{NPH}$ ) was started at a dose of $0.6 \mathrm{U} / \mathrm{kg} /$ day. Sequencing analysis of the ABCC8, KCNJ11, INS, and $G C K$ genes were negative. Parental consent was not obtained for further genetic testing.

A pipeline for the diagnosis and follow-up of patients with NDM is suggested in Figure 2. Pedigrees of the cases with the family member with diabetes (patients 1, 2, 3, 7, and 11) are illustrated in online suppl. Figure; see www. karger.com/doi/10.1159/000512247 for all online suppl. material.

\section{Discussion}

Major advances in molecular techniques have led to better understanding of the genetic basis of NDM over the last 2 decades. In this cohort, patients were followed from the date of diagnosis of diabetes and categorized as PNDM or TNDM during follow-up. Only 1 subject (P\#8) with the KCNJ11 mutation had TNDM, and 93.3\% of subjects had PNDM.

Infants with NDM may present with vague signs that overlap with other conditions such as infections. Clinical presentation may range from asymptomatic hyperglycaemia to polydipsia, failure to thrive, vomiting and irritability, or acute symptoms with severe dehydration, seizure, and ketoacidosis. In our cohort, 2 patients with $A B C C 8$ mutations $(\mathrm{P} \# 1$ and $\mathrm{P} \# 3)$ presented with seizures and DKA was present in 1 case with a KCNJ11 mutation (P\#8) and 2 cases without a genetic diagnosis.

Treatment and clinical management of NDM still represent a challenge. Insulin treatment has traditionally been the first and only choice for NDM therapy. After stabilization via intravenous insulin, patients are usually switched to subcutaneous forms using either regular insulin or rapid-acting analogue plus basal insulin. All of the patients in our cohort were managed as described. Basal insulin coverage can be regulated using the intermediate-acting (NPH) or insulin analogues (glargine or detemir). Insulin treatment in infants must be carefully designed. Continuous subcutaneous insulin infusion (CSII) was successfully included in the management of NDM, providing more flexibility in time and insulin amounts [18-20]. CSII was discussed with some of the families in our cohort, and they felt they would prefer to 
continue with MDI. None of the patients in our cohort used CSII in infancy.

KCNJ11 mutations most commonly cause PNDM, whereas $A B C C 8$ mutations are more likely to lead transient diabetes [21]. Interestingly, $A B C C 8$ mutations were more frequent than KCNJ11 mutations in our PNDM cohort. This is likely due to the high rate of consanguinity in our cohort as recessively acting mutations are more common in $A B C C 8$ than KCNJ11. Varying degrees of neurologic impairment are often found in patients with NDM due to $A B C C 8$ and $K C N J 11$ mutations $[22,23]$. None of the subjects in our cohort had neurodevelopmental delay or features of DEND (developmental delay, epilepsy, and neonatal diabetes) syndrome, according to initial neurological assessments at diagnosis. However, follow-up data were limited for the patient with the KCNJ11 p.R201C mutation which has been previously reported to be associated with mild developmental delay.

Most patients with activating mutations in KCNJ11 or $A B C C 8$ can be transitioned from insulin to SU with improvement in metabolic control $[8,24]$. Because KATP channels are also being expressed in the brain, SU treatment is able to improve neurological impairment in some cases [25] in addition to leading to better metabolic control. Importantly, it is reported that those who transfer to $\mathrm{SU}$ at a younger age require a lower dose and are more likely to remain well controlled on monotherapy, while those who transition later ( $>13$ years) are more likely to need additional treatment $[8,10,25]$. In contrast, although $\mathrm{P} \# 1$ in our study has been transitioned to $\mathrm{SU}$ at a later age, he had no insulin requirement later on. His sibling, $\mathrm{P} \# 2$, was transitioned to $\mathrm{SU}$ in a relatively earlier age than his brother; however, he had requirement for both SU and MDI. This is likely to be due to non-compliance to treatment regimens. $\mathrm{P} \# 3$ was also transitioned at a later age (16.3 years of age) and required both SU and MDI, but insulin dose decreased significantly requiring only small doses of basal insulin. Severe hypoglycaemic episodes were not reported in any of the 3 patients treated with SU even at high doses ( $2.0 \mathrm{mg} / \mathrm{kg} /$ day $)$, in keeping with previous reports [26].

PTF1A is a transcription factor important for brain and pancreas development [18]. In keeping with this, these homozygous null mutations in the gene have been shown to cause pancreatic and cerebellar agenesis [27]. More recently, biallelic mutations in a novel enhancer 25 $\mathrm{kb}$ downstream from the PTF1A gene have been identified [18]. These mutations cause isolated pancreatic agenesis without cerebellar involvement, suggesting the en- hancer is specific to the pancreas $[18,28]$. Three patients in our cohort $(20 \%)$ had PTF1A-distal enhancer mutations, and this is more common than reported in other cohorts. Given that all 3 patients had the same mutation, it is possible that this represents a founder effect in patients in our region. Similar to previous reports, all 3 patients had pancreatic hypoplasia without cerebellar agenesis and birth weight SDS were significantly low, as observed in the previously reported PTF1A cases. Evidence of phenotypic variability has been reported in patients with PTF1A enhancer mutations [28]. Although the majority are diagnosed in the first month of life, diabetes with onset later in life was also reported, suggesting that PTF1A enhancer mutations may also be a cause for lateonset monogenic diabetes [29].

Our cohort included only 1 female patient ( $\mathrm{P} \# 7$ with PTF1A enhancer mutation). Although it would not be expected to have a specific sex predominance in the NDM cohort since the majority of genetic causes have autosomal inheritance, an enrichment for males in PNDM cohorts has been observed previously. In the study of Khawaga et al. [30] describing the clinical and genetic characteristics of 9 PNDM cases from the state of Qatar, the male to female ratio was $2: 1$. In another study, the female to male ratio was reported as 5/0 in TNDM and $4 / 13$ in PNDM cases $(p=0.006)$ [5]. Finally, in a large study of 1,020 patients with NDM published by De Franco et al. [1], there were 571 males and 449 females $(p=0.006)$. Further studies are needed to assess the possible causes of this apparent sex bias.

In countries with high rates of consanguinity, WRS is the most common cause of NDM. Clinical features such as skeletal dysplasia (epiphyseal and spondyloepiphyseal dysplasia), cerebellar cortical dysplasia, hepatic and renal dysfunction, cardiomegaly, and mental retardation often develop after infancy [31, 32]. EIF2AK3 should be included in all NDM genetic testing panels, especially when used to test patients born to consanguineous parents, even if skeletal dysplasia and liver dysfunction are not present [33]. Although WRS represents a major cause of NDM in the Middle East [31], only 1 EIF2AK3 mutation was found in our patient cohort. Until now, data on fewer than 100 children with WRS have been published [34, 35] suggesting careful evaluation of glycaemic control, as well as renal and pancreatic function and growth, is fundamental. These patients are prone to repeated episodes of acute liver failure which may increase in severity with time with the risk of life-threatening fulminant liver failure. Liver transplantation is important, both as rescue treatment and as elective treatment, for patients with 
WRS [35]. Unfortunately, our case had no regular visits to our unit and died due to acute liver failure.

Patients with INS homozygous mutations have low birth weight due to reduced insulin secretion in utero. Postnatal growth failure is also frequent. Our patient with a homozygous INS promoter mutation had significantly low birth weight SDS and postnatal growth failure with a final height of -3.2 SDS. Insulin levels were undetectable in our case, demonstrating the virtual absence of proper insulin production $[36,37]$.

TRMA is a recessively inherited disorder characterized by early onset diabetes, sensorineural hearing loss, and megaloblastic anaemia. Other rare clinical features include congenital heart disease, arrhythmias, retinal degeneration, optic atrophy, aminoaciduria, short stature, and situs inversus. $1^{\circ}$ atrioventricular block was also detected in our patient with TRMA. The gene responsible for TRMA, SLC19A2, codes for a high-affinity thiamine transporter protein (THTR-1) $[38,39]$, and treatment with thiamine (vitamin B1) can improve haematological and endocrine function, but neurological manifestations and deafness (which is progressive and irreversible) do not respond as well. Our patient with TRMA was treated with thiamine which improved the anaemia.

In a previous study reporting 22 patients from Turkey, biallelic GCK mutations were found to be a common cause of PNDM [5]; however, the most frequent cause in our cohort was KATP channel mutations (predominantly $A B C C 8$ ) and PTF1A enhancer mutations. Another difference from this study was that none of the patients in our cohort in whom comprehensive genetic testing could be performed had a chromosome 6q24 methylation abnormality. These results highlight the genetic heterogeneity of NDM even within the same country.

Most of the studies and reported cases of NDM describe the clinical and biochemical characteristics of patients at diagnosis. This is one of the few studies reporting the anthropometric characteristics (10 patients) and the final height (ABCC8 mutation: 3, INS mutation: 1) data of patients with NDM. Indeed, further studies describing follow-up data of large NDM patient cohorts would be extremely valuable to help improve treatment protocols and highlight the importance of compliance to treatment.

In conclusion, although the consanguinity ratio was high, KATP channel and PTF1A enhancer mutations were the most frequent aetiology in our cohort, not the recessively inherited WRS. In the cases with KATP channel mutations and TRMA we report, treatment was modified after genetic testing. These results highlight the im- portance of early and accurate molecular testing for all cases with NDM due to potential consequences for the treatment and prognosis.

\section{Acknowledgements}

The authors wish to express their gratitude to the parents and the patients who participated in this study.

\section{Statement of Ethics}

All the parents in the study gave their written informed consent for the genetic testing of their children. Written informed consent was obtained from the parents for publication of this study and any accompanying images. This study was approved by the Local Ethics Committee of Istanbul Faculty of Medicine (2019/1212).

\section{Conflict of Interest Statement}

The authors have no conflicts of interest to declare.

\section{Funding Sources}

Genetic testing was funded by the Wellcome Trust through a senior investigator award (grant WT098395/Z/12/Z). E.D.F. is a Diabetes UK RD Lawrence Fellow (19/005971). S.E.F. has a Sir Henry Dale Fellowship jointly funded by the Wellcome Trust and the Royal Society (105636/Z/14/Z).

\section{Author Contributions}

Z.Y.A., E.K.O., S.P., R.B., F.B., and F.D. designed the research study and analyzed the data. Z.Y.A., E.D.F., S.E.F., S.P., F.B., and F.D. did the research and wrote the paper. E.D.F. and S.E.F. performed the molecular analyses. All authors read and approved the final manuscript for publication.

\section{References}

1 De Franco E, Flanagan SE, Houghton JA, Lango Allen H, Mackay DJ, Temple IK, et al. The effect of early, comprehensive genomic testing on clinical care in neonatal diabetes: an international cohort study. Lancet. 2015; 386(9997):957-63.

2 Greeley SA, Tucker SE, Naylor RN, Bell GI, Philipson LH. Neonatal diabetes mellitus: a model for personalized medicine. Trends Endocrinol Metab. 2010;21(8):464-72.

3 Flanagan SE, Edghill EL, Gloyn AL, Ellard S, Hattersley AT. Mutations in KCNJ11, which encodes Kir6.2, are a common cause of diabetes diagnosed in the first 6 months of life, with the phenotype determined by genotype. Diabetologia. 2006;49(6):1190-7. 
4 Iafusco D, Massa O, Pasquino B, Colombo C, Iughetti L, Bizzarri C, et al. Minimal incidence of neonatal/infancy onset diabetes in Italy is 1: 90,000 live births. Acta Diabetol. 2012;49: $405-8$.

5 Demirbilek H, Arya VB, Ozbek MN, Houghton JA, Baran RT, Akar M, et al. Clinical characteristics and molecular genetic analysis of 22 patients with neonatal diabetes from the South-Eastern region of Turkey: predominance of non-KATP channel mutations. Eur J Endocrinol. 2015;172:697-705.

6 Habeb AM, Al-Magamsi MS, Eid IM, Ali MI, Hattersley AT, Hussain K, et al. Incidence, genetics, and clinical phenotype of permanent neonatal diabetes mellitus in northwest Saudi Arabia. Pediatr Diabetes. 2012;13(6):499505.

7 Pearson ER, Flechtner I, Njølstad PR, Malecki MT, Flanagan SE, Larkin B, et al. Switching from insulin to oral sulfonylureas in patients with diabetes due to Kir6.2 mutations. N Engl J Med. 2006;355(5):467-77.

8 Babenko AP, Polak M, Cavé H, Busiah K, Czernichow P, Scharfmann R, et al. Activating mutations in the $\mathrm{ABCC} 8$ gene in neonatal diabetes mellitus. N Engl J Med. 2006;355(5): 456-66.

9 Støy J, Greeley SA, Paz VP, Ye H, Pastore AN, Skowron KB, et al. Diagnosis and treatment of neonatal diabetes: a United States experience. Pediatr Diabetes. 2008;9(5):450-9.

10 Rafiq M, Flanagan SE, Patch AM, Shields BM, Ellard S, Hattersley AT; Neonatal Diabetes International Collaborative Group. Effective treatment with oral sulfonylureas in patients with diabetes due to sulfonylurea receptor 1 (SUR1) mutations. Diabetes Care. 2008;31(2): 204-9.

11 Iafusco D, Bizzarri C, Cadario F, Pesavento R, Tonini G, Tumini S, et al. No beta cell desensitisation after a median of 68 months on glibenclamide therapy in patients with KCNJ11associated permanent neonatal diabetes. Diabetologia. 2011;54(10):2736-8

12 Rubio-Cabezas O, Patch AM, Minton JA, Flanagan SE, Edghill EL, Hussain K, et al. Wolcott-Rallison syndrome is the most common genetic cause of permanent neonatal diabetes in consanguineous families. J Clin Endocrinol Metab. 2009;94(11):4162-70.

13 Brickwood S, Bonthron DT, Al-Gazali LI, Piper K, Hearn T, Wilson DI, et al. WolcottRallison syndrome: pathogenic insights into neonatal diabetes from new mutation and expression studies of EIF2AK3. J Med Genet. 2003;40(9):685-9.

14 Edghill EL, Dix RJ, Flanagan SE, Bingley PJ, Hattersley AT, Ellard S, et al. HLA genotyping supports a nonautoimmune etiology in patients diagnosed with diabetes under the age of 6 months. Diabetes. 2006;55(6):1895-8

15 De Franco E. From biology to genes and back again: gene discovery for monogenic forms of beta-cell dysfunction in diabetes. J Mol Biol. 2020;432(5):1535-50.

16 Ellard S, Lango Allen H, De Franco E, Flanagan SE, Hysenaj G, Colclough $\mathrm{K}$, et al. Improved genetic testing for monogenic diabetes using targeted next-generation sequencing. Diabetologia. 2013;56(9):1958-63.

17 Aydin BK, Bundak R, Baş F, Maraş H, Saka N, Günöz H, et al. Permanent neonatal diabetes mellitus: same mutation, different glycemic control with sulfonylurea therapy on longterm follow-up. J Clin Res Pediatr Endocrinol. 2012;4(2):107-10.

18 Weedon MN, Cebola I, Patch AM, Flanagan SE, De Franco E, Caswell R, et al. Recessive mutations in a distal PTF1A enhancer cause isolated pancreatic agenesis. Nat Genet. 2014; 46(1):61-4.

19 Rabbone I, Barbetti F, Gentilella R, Mossetto G, Bonfanti R, Maffeis C, et al. Insulin therapy in neonatal diabetes mellitus: a review of the literature. Diabetes Res Clin Pract. 2017;129: 126-35.

20 Karges B, Meissner T, Icks A, Kapellen T, Holl RW. Management of diabetes mellitus in infants. Nat Rev Endocrinol. 2011;8(4):201-11.

21 Letourneau LR, Greeley SAW. Congenital forms of diabetes: the beta-cell and beyond. Curr Opin Genet Dev. 2018;50:25-34.

22 Busiah K, Drunat S, Vaivre-Douret L, Bonnefond A, Simon A, Flechtner I, et al. Neuropsychological dysfunction and developmental defects associated with genetic changes in infants with neonatal diabetes mellitus: a prospective cohort study [corrected]. Lancet Diabetes Endocrinol. 2013;1(3):199-207.

23 Bowman P, Hattersley AT, Knight BA, Broadbridge E, Pettit L, Reville M, et al. Neuropsychological impairments in children with KCNJ11 neonatal diabetes. Diabet Med. 2017; 34(8):1171-3.

24 Bowman P, Sulen Å, Barbetti F, Beltrand J, Svalastoga P, Codner E, et al. Effectiveness and safety of long-term treatment with sulfonylureas in patients with neonatal diabetes due to KCNJ11 mutations: an international cohort study. Lancet Diabetes Endocrinol. 2018;6(8):637-46.

25 Fendler W, Pietrzak I, Brereton MF, Lahmann C, Gadzicki M, Bienkiewicz M, et al. Switching to sulphonylureas in children with iDEND syndrome caused by KCNJ11 mutations results in improved cerebellar perfusion. Diabetes Care. 2013;36(8):2311-6.

26 Thurber BW, Carmody D, Tadie EC, Pastore AN, Dickens JT, Wroblewski KE, et al. Age at the time of sulfonylurea initiation influences treatment outcomes in KCNJ11-related neonatal diabetes. Diabetologia. 2015;58(7): 1430-5.

27 Al-Shammari M, Al-Husain M, Al-Kharfy T, Alkuraya FS. A novel PTF1A mutation in a patient with severe pancreatic and cerebellar involvement. Clin Genet. 2011;80(2):196-8.
28 Houghton JA, Swift GH, Shaw-Smith C, Flanagan SE, de Franco E, Caswell R, et al. Isolated pancreatic aplasia due to a hypomorphic PTF1A mutation. Diabetes. 2016;65(9):2810-5.

29 Gabbay M, Ellard S, De Franco E, Moisés RS. Pancreatic agenesis due to compound heterozygosity for a novel enhancer and truncating mutation in the PTF1A gene. J Clin Res Pediatr Endocrinol. 2017;9(3):274-7.

30 Khawaga SA, Mohammed I, Saraswathi S, Haris B, Hasnah R, Saeed A, et al. The clinical and genetic characteristics of permanent neonatal diabetes (PNDM) in the state of Qatar. Mol Genet Genomic Med. 2019;7:00753.

31 Abbasi F, Habibi M, Enayati S, Bitarafan F, Razzaghy-Azar M, Sotodeh A, et al. A genotype-first approach for clinical and genetic evaluation of Wolcott-Rallison syndrome in a large cohort of Iranian children with neonatal diabetes. Can J Diabetes. 2018;42(3):272-5.

32 Stewart FJ, Carson DJ, Thomas PS, Humphreys M, Thornton C, Nevin NC. WolcottRallison syndrome associated with congenital malformations and a mosaic deletion 15q 1112. Clin Genet. 1996;49(3):152-5.

33 Delépine $M$, Nicolino $M$, Barrett T, Golamaully M, Lathrop GM, Julier C. EIF2AK3, encoding translation initiation factor 2-alpha kinase 3 , is mutated in patients with WolcottRallison syndrome. Nat Genet. 2000;25(4): 406-9.

34 Habeb AM, Deeb A, Johnson M, Abdullah M, Abdulrasoul M, Al-Awneh $\mathrm{H}$, et al. Liver disease and other comorbidities in Wolcott-Rallison syndrome: different phenotype and variable associations in a large cohort. Horm Res Paediatr. 2015;83(3):190-7.

35 Lundgren M, De Franco E, Arnell H, Fischler B. Practical management in Wolcott-Rallison syndrome with associated hypothyroidism, neutropenia, and recurrent liver failure: a case report. Clin Case Rep. 2019;7(6):1133-8.

36 Deeb A, Habeb A, Kaplan W, Attia S, Hadi S, Osman A, et al. Genetic characteristics, clinical spectrum, and incidence of neonatal diabetes in the Emirate of Abu Dhabi, United Arab Emirates. Am J Med Genet A. 2016; 170(3):602-9.

37 Courtney R, Gamble C, Arango ML, Shah A, Rubio NI, Nguyen J, et al. Novel homozygous likely-pathogenic intronic variant in INS causing permanent neonatal diabetes in siblings. J Pediatr Endocrinol Metab. 2016;29(9): 1089-93.

38 Rubio-Cabezas O, Klupa T, Malecki MT. Permanent neonatal diabetes mellitus: the importance of diabetes differential diagnosis in neonates and infants. Eur J Clin Invest. 2011; 41(3):323-33.

39 Labay V, Raz T, Baron D, Mandel H, Williams $\mathrm{H}$, Barrett T, et al. Mutations in SLC19A2 cause thiamine-responsive megaloblastic anaemia associated with diabetes mellitus and deafness. Nat Genet. 1999;22(3):300-4. 